\title{
Clock genes in calendar cells as the basis of annual timekeeping in mammals - a unifying hypothesis
}

\author{
G A Lincoln, $\mathbf{H}$ Andersson and A Loudon ${ }^{\mathbf{1}}$ \\ Medical Research Council, Human Reproductive Sciences Unit, Centre for Reproductive Biology, The University of Edinburgh, Chancellor's Building, \\ 49 Little France Crescent, Edinburgh, EH16 4SB, UK \\ ${ }^{1}$ School of Biological Sciences, University of Manchester, Oxford Road, Manchester M13 9PT, UK \\ (Requests for offprints should be addressed to G Lincoln; Email: g.lincoln@hrsu.mrc.ac.uk)
}

\begin{abstract}
Melatonin-based photoperiod time-measurement and circannual rhythm generation are long-term time-keeping systems used to regulate seasonal cycles in physiology and behaviour in a wide range of mammals including man. We summarise recent evidence that temporal, melatonincontrolled expression of clock genes in specific calendar cells may provide a molecular mechanism for long-term timing. The agranular secretory cells of the pars tuberalis (PT) of the pituitary gland provide a model cell-type because they express a high density of melatonin (mt1) receptors and are implicated in photoperiod/circannual regulation of prolactin secretion and the associated seasonal biological responses. Studies of seasonal breeding hamsters and sheep indicate that circadian clock gene expression in the PT is modulated by photoperiod via the melatonin signal. In the Syrian and Siberian hamster PT, the high amplitude Per1 rhythm associated with dawn is suppressed under short photoperiods, an effect that is mimicked by melatonin treatment. More extensive studies in sheep
\end{abstract}

show that many clock genes (e.g. Bmal1, Clock, Per1, Per2, Cry 1 and Cry2) are expressed in the $\mathrm{PT}$, and their expression oscillates through the 24-h light/darkness cycle in a temporal sequence distinct from that in the hypothalamic suprachiasmatic nucleus (central circadian pacemaker). Activation of Per1 occurs in the early light phase (dawn), while activation of Cry1 occurs in the dark phase (dusk), thus photoperiod-induced changes in the relative phase of $\mathrm{Per}$ and $\mathrm{Cr} y$ gene expression acting through PER/CRY protein/protein interaction provide a potential mechanism for decoding the melatonin signal and generating a long-term photoperiodic response. The current challenge is to identify other calendar cells in the central nervous system regulating long-term cycles in reproduction, body weight and other seasonal characteristics and to establish whether clock genes provide a conserved molecular mechanism for long-term timekeeping.

Journal of Endocrinology (2003) 179, 1-13

\section{Long-term timers}

Long-term timing mechanisms that allow organisms to anticipate environmental events months or years in advance and to optimise survival and reproductive success are widespread in nature. Cycles in gonadal activity, pelage moult, food intake, body weight and hibernation are familiar annual events in many mammals. The cycles are precisely timed such that the offspring are born at the most favourable season, or the animal is physiologically prepared in advance for the rigours of winter. The Syrian and Siberian hamster, Soay and Suffolk sheep, various ground squirrels, mink, arctic fox, black bear, Bennet's wallaby, red deer and rhesus monkey are some of the best studied species, and each has its specific set of timed adaptations. These well-known species derive from temperate and cold climates, but long-term cyclicity in reproduction is also a feature of mammals from the tropics. Here, the individuals in a population may be synchronised in their cycles of breeding and migration to anticipate the rainy season or to reduce predation (e.g. wildebeast, tropical fruit bats and lemurs), or asynchronous to reduce male sexual competition (e.g. male Asian and African elephant and tropical deer). In the case of the axis deer living close to the equator, males express a testicular cycle, and the associated overt antler cycle, with a periodicity of approximately a year, while each individual adopts its own timing. The tropical pattern persists even after the animals have been transferred to northern latitudes (e.g. to the London zoo) and bred for many generations (Loudon \& Curlewis 1988, Lincoln et al. 1996b). 

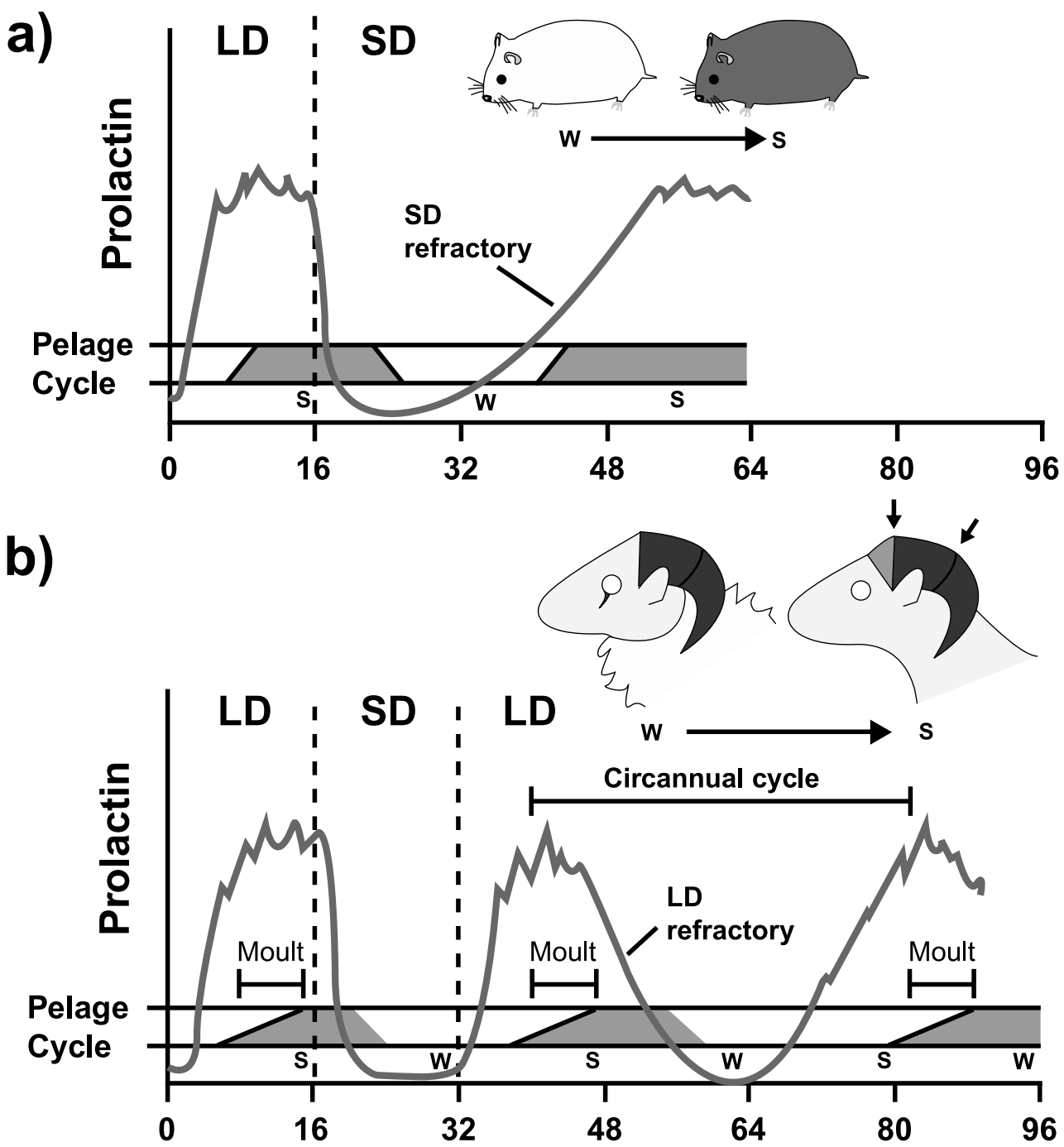

Weeks

Figure 1 Long-term changes in prolactin secretion and the associated pelage/moult cycle in (a) male Siberian hamster and (b) male Soay sheep exposed to alternating periods of LD ( $16 \mathrm{~h}$ light: $8 \mathrm{~h}$ darkness, LD) and SD (8 h light:16 h darkness, SD). As in many photoperiodic mammals, LD activate and SD inhibit prolactin release, and the pelage responds accordingly. In the hamster, exposure to prolonged SD results in the development of refractoriness with the recovery of the prolactin secretion from 12-38 weeks (SD refractory state) and reversion from the white, winter (w) to agouti, summer (s) pelage. In the sheep, exposure to prolonged LD results in an initial refractory response from 12-36 weeks (LD refractory state) that merges into the expression of a circannual cycle; horn growth is suppressed during the winter physiology leaving a permanent record of the cycles as rings in the horns (see arrows).

Two types of mechanisms are used by mammals for long-term timekeeping. The first - photoperiodism registers the change in the annual cycle in daylength and translates this into the timed control of physiology and behaviour (Tamarkin et al. 1985). Photoperiodism generates timing through photoinduction which is a genetically programmed response to a change from short to long days, or vice versa. The associated process of photorefractoriness is also driven through this pathway and produces changes in physiology over weeks or months that may be a reversal of the initial response, producing a timed cycle. Both aspects allow for appropriate phasing of the animals' biology to the sidereal year. The timing responses are illustrated in Fig. 1 for the photoperiodic regulation of prolactin secretion and consequent pelage moult cycle in the Siberian hamster and Soay sheep. Typically for most photoperiodic mammals, 
long days (LD) activate prolactin release and a summer physiology, while short days (SD) suppress prolactin and produce a winter condition including the development of the denser insulating pelage. The Siberian hamster shows a characteristic refractory response to prolonged SD (termed SD refractoriness), with blood prolactin concentrations returning to summer values within 38 weeks, and the agouti, pigmented pelage redevelops despite the persistence of the short photoperiod (Bockers et al. 1997, Kuhlmann et al. 2003). Such refractory responses are adaptive in the wild because they allow the animal to begin to adopt a spring physiology before emerging from hibernation.

The second timing mechanism - circannual rhythm generation - is a notable feature in many long-lived animals that survive and breed over several seasons, and occurs in mammalian groups from all latitudes. These species express annual cycles in the wild, and continue to express circannual cyclicity when maintained indoors under constant conditions, often for many years or throughout life (Gwinner 1986, Woodfill et al. 1994). In some animals (e.g. hibernating ground squirrels, tropical fruit bats), the intrinsic circannual cycle predominates irrespective of photoperiod, while in others (e.g. sika deer, Suffolk sheep) both circannual timing and photoperiodism are combined to regulate seasonality. Here, the ambient photoperiod may dictate whether or not the long-term rhythms are expressed, and the development of photorefractoriness under a constant photoperiod is indistinguishable from the start of the circannual cycle. This is evident in the long-term control of prolactin secretion in the sheep where LD are permissive to the expression of the circannual rhythm, and LD refractoriness is the first manifestation of the intrinsic rhythm under prolonged LD (Fig. 1). Consequently, the interval timer that underlies the development of photorefractoriness and the generation of the circannual rhythm may be the same, and represents the ancestral form of long-term timekeeping (Prendergast et al. 2002). This suggests a single basic molecular mechanism underlying circannual rhythm generation, as has been demonstrated so elegantly for circadian rhythm generation (Reppert \& Weaver 2002).

In the case of circadian timing, this is generated endogenously by a cell autonomous mechanism involving a small number of core clock genes (about 12 genes identified currently) that interact to control their own transcription. In mammals, clock genes are expressed in the suprachiasmatic nucleus (SCN), where they form the basis for its circadian pacemaker function. The positivedrive to the daily clock is constituted by two, basic helix-loop-helix, PAS-domain containing transcription factor genes, called Clock and Bmal1. The protein products of these genes form heterodimeric complexes that control the transcription of other clock genes, notably three Period (Per1/Per2/Per3) genes and two Cryptochrome (Cry1/ $\mathrm{Cry} 2$ ) genes, which in turn provide the negative feedback signal that shuts down the Clock/Bmal drive to complete the circadian cycle. Other clock genes provide additional negative and positive transcriptional/translational feedback loops to form the rest of the core clockwork, which has been characterised in rodents by a transgenic genedeletion methodology. Clock gene expression oscillates because of the delay in the feedback loops, regulated in part by phosphorylation of the clock proteins that control their stability, nuclear re-entry and transcription complex formation. Clock genes are expressed in many other neural and peripheral tissues in a tissue-specific fashion, often with unknown function. Critical to the current review, clock genes are expressed in tissues involved in long-term timekeeping (Fig. 2).

\section{Melatonin signalling and calendar cells}

In mammals, photoperiodism depends on the way the pineal gland transduces photoperiod into a $24-\mathrm{h}$ melatonin signal, and how melatonin duration is decoded in melatonin-responsive tissues that govern specific aspects of seasonal physiology and behaviour (Lincoln 1999, Goldman 2001). In this sensory/neuroendocrine relay (Fig. 2), light acts exclusively through photoreceptor cells in the retina to control melatonin production by two different mechanisms. First, periodic light stimuli every $24 \mathrm{~h}$ act to entrain the circadian clockwork of the SCN, and to shape the waveform of clock genes and electrophysiological activity of SCN neurons (Sumova et al. 1995, Nuesslein-Hildesheim et al. 2000). The SCN regulates the timing of diurnal rhythms of activity/sleep, body temperature, pituitary activity and many other aspects of daily rhythmicity, as well as the nocturnal-associated release of melatonin. Secondly, light inhibits melatonin release irrespective of circadian time, via a retinal-hypothalamicsympathetic innervation to the pinealocytes and the control of the rate-limiting enzyme $\mathrm{N}$-acetyltransferase (NAT) (Klein et al. 1997). These two controls dictate that melatonin is secreted only at night, and that the duration of melatonin release varies quantitatively with nightlength, and therefore daylength. In photoperiodic rodents the SCN appears to govern the shape of the encoding melatonin signal through the transcriptional control of NAT (Illnerova \& Sumova 1997), whereas in ungulates the masking effect of light, through light-induced degradation of NAT, is more important (Picazo \& Lincoln 1995, Stehle et al. 2001). Melatonin is secreted into the peripheral blood and cerebral spinal fluid where the highest concentrations occur (Malpaux et al. 2001). The lipophylic nature of melatonin ensures that all tissues receive an endocrine index of time of day (phase of increased melatonin concentrations) and time of year (duration of increased melatonin concentrations - long in winter and short in summer).

The decoding of the changes in melatonin signal duration that govern seasonal physiology depends on 


\section{a) melatonin signal generator}

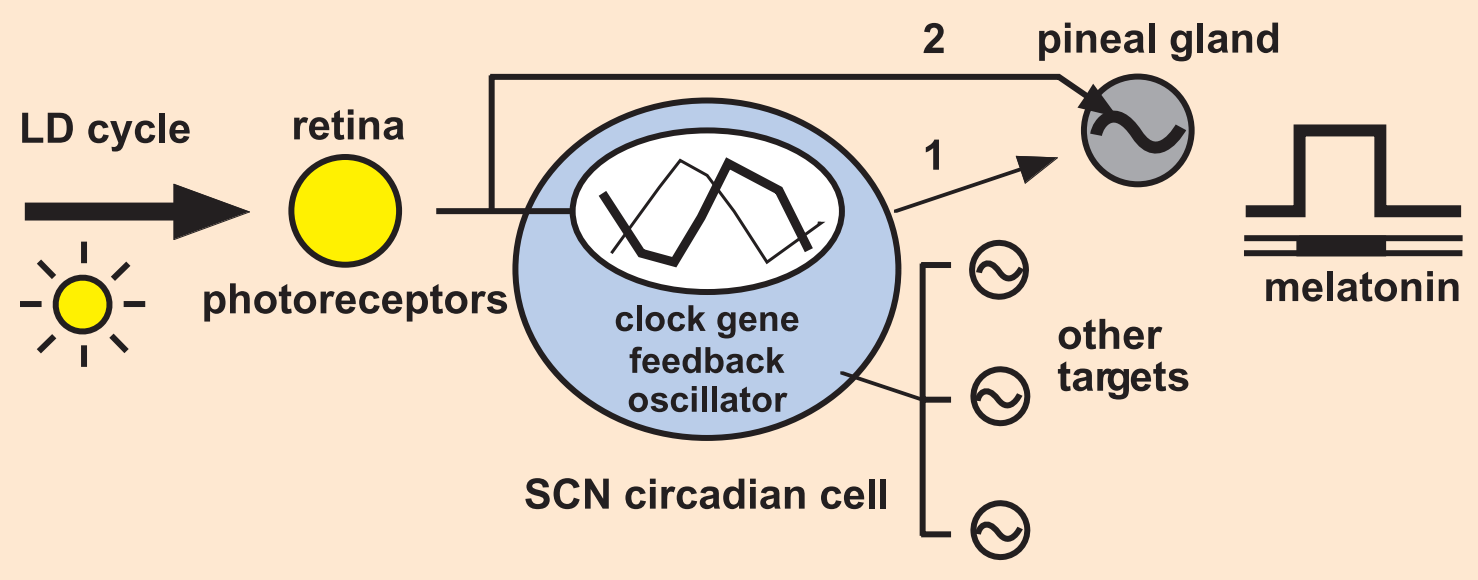

\section{b) melatonin decoder in pituitary gland}

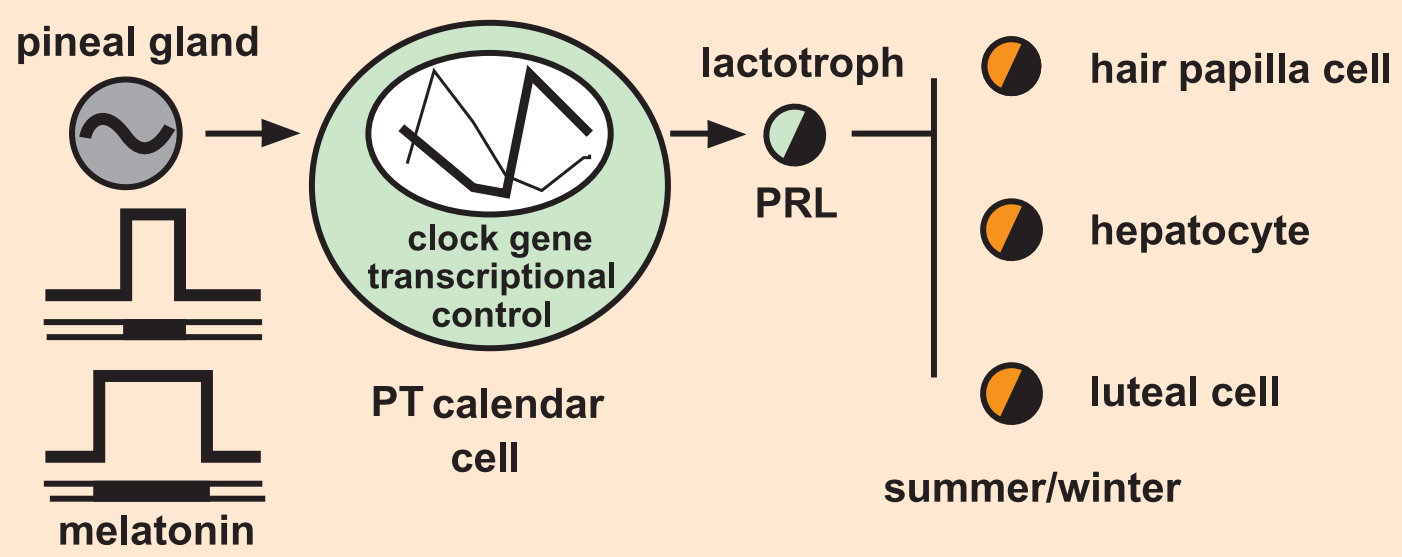

Figure 2 Photoperiodism in mammals depends on: (a) the generation of a 24-h nocturnal melatonin signal by the pineal gland that reflects the nightlength and thus daylength, and (b) the decoding of this signal in specialised target tissues, including the pars tuberalis (PT) of the pituitary gland that is thought to regulate seasonal cycles in prolactin secretion from lactotrophs. Light of the daily light/darkness cycle is perceived by photoreceptors in the retina, and affects the melatonin signal through entrainment of the SCN circadian cell (pacemaker pathway - 1) and by inhibition of melatonin production (inhibitory pathway - 2). The wave form of circadian clock gene expression, and patterns of electrophysiological activity in the SCN pacemaker, are known to vary with photoperiod; however long-term time keeping depends principally on the melatonin target cells - here called calendar cells. These are thought to use a clock gene-based mechanism to decode melatonin duration to produce a long or short day physiology. For the PT/lactotroph axis, LD activate an increase in prolactin secretion and drive associated seasonal changes in the hair papilla cell (pelage moult cycle), hepatocyte (liver function), luteal cell (uterine activity/implantation) and other tissues.

specialised melatonin target cells in the brain, pituitary gland and perhaps in peripheral tissues. These cells are required to express high affinity melatonin receptors to register the systemic signal, and to discriminate between short $(\sim 6-10 \mathrm{~h})$ and long $(\sim 12-16 \mathrm{~h})$ daily exposure to melatonin. The 'duration sensors' are here termed calendar cells because they have both the machinery to register changes in signal duration and to generate a long-term physiological and/or behavioural response (Fig. 2b).

To date, the best characterised calendar cells are the agranular, secretory cells of the pars tuberalis (PT) of the pituitary gland, implicated in the seasonal regulation of prolactin secretion and its dependent physiology. Prolactin secretion is increased under LD (summer) and decreased 
under SD (winter), as described above, and contributes to the seasonal regulation of the moult cycle, food intake and energy metabolism, gonadal activity, pregnancy, lactation and/or delayed implantation, across a variable spectrum of mammalian species. The PT cells that register the melatonin signal are thought to dictate the secretion of prolactin from the lactotrophs in the pars distalis, through the production of prolactin releasing factors (tuberalins) that function as paracrine regulators within the pituitary gland (Hazlerigg et al. 1996, Morgan et al. 1996). In vitro studies in the Syrian hamster indicate that PT tuberalins are up-regulated under LD, down-regulated under SD, and can be suppressed by melatonin (Stirland et al. 2001, Johnston et al. 2003).

\section{Decoding the melatonin signal in the PT calendar cell}

The importance of the PT was first recognised based on its high density binding of $\mathrm{I}^{125}$ iodomelatonin in sheep and hamster, higher that in any other tissue, and because of its strategic location at the interface between the median eminence and the pituitary gland (Morgan et al. 1994). Subsequently, the PT has been adopted as a model system to investigate the molecular mechanisms involved in decoding melatonin signal duration and long-term timing (Morgan 2000, Hazlerigg et al. 2001). This rests on the ability to readily manipulate PT cells in vitro using primary cell cultures from animals set up on specific photoperiods, and the ability to study the long-term PT-control of prolactin secretion in vivo using hypothalamo-pituitary disconnected (HPD) sheep where the complications of direct inputs from the hypothalamus are removed (see below). Also, there has been notably little progress in identifying the phenotype of other melatonin target/ calendar cells in the mediobasal hypothalamus $(\mathrm{MBH})$, that regulate seasonal gonadotrophin secretion and the reproductive axis, or the seasonal food intake, body weight, and energy balance axes (Morgan \& Mercer 2002).

Melatonin acts through the high affinity melatonin mt1 receptor expressed on the surface of PT cells, and suppresses forskolin-induced cAMP accumulation by the inhibition of adenylyl cyclase (Hazlerigg et al. 1993, Reppert et al. 1994). This produces a dose-dependent decline in a range of cAMP-dependent processes including activation of protein kinase $\mathrm{A}$, phosphorylation of cAMP response element binding protein, production of inducible cAMP early repressor (ICER) (McNulty et al. 1994), and the induction of the early response gene protein, c-fos. These effects are induced by picomolar concentrations of melatonin in the physiological range, and are essentially immediate. Notably for duration decoding, prolonged exposure to melatonin over periods of 8 or $16 \mathrm{~h}$ in order to mimic more closely the physiological profiles of melatonin, causes duration-dependent changes in the sensitivity of the intracellular signalling response. This occurs as a progressive increase in forskolin-induced cAMP accumulation in the face of constant melatonin, and a decrease in the inhibitory response to a second exposure to melatonin 8-16 h later. This indicates that melatonin may act through a cAMP sensitization/desensitization mechanism to decode the melatonin signal duration in vivo to regulate the output response (Hazlerigg et al. 1993; von Gall et al. 2002).

The measurement of the 24-h patterns of expression of two acutely inducible genes (Per1 and ICER) in the PT and SCN by in situ hybridisation and immunocytochemistry has provided more definitive information on the regulation by melatonin (Morgan et al. 1998, Messager et al. 1999). These studies have been carried out in sheep and Syrian and Siberian hamsters housed under both LD and SD to provide contrasting phenotypes. The results show that Per1 and ICER expression in the PT varies markedly throughout the 24-h LD cycle, with peak expression for both genes in the early light phase after the decline in melatonin secretion $(\mathrm{ZT} 3$, where $\mathrm{ZT} 0=$ time of lights on). The amplitude of this daytime peak significantly increases under long photoperiods; on short photoperiods the Per1 rhythm is either reduced in amplitude or suppressed completely in the Siberian hamster within 12 weeks (Messager et al. 2000), and in the Syrian hamster within 28 weeks (Johnston et al. 2003). This contrasts with the waveform of gene expression in the SCN, where photoperiod regulates the duration rather than the amplitude of expression (Messager et al. 2000, Johnston et al. 2003). The PT pattern of gene expression is causally regulated by the diurnal melatonin rhythm because an injection of melatonin before lights-on blocks, or delays, the morning increase in Per1 and ICER gene expression in the PT. Expression of Per1 in the PT is absent in pinealectomised animals (Messager et al. 2001) and also in strains of mice which lack melatonin (von Gall et al. 2002). Thus, it is likely that activation of gene expression at dawn represents a dis-inhibition response due to melatonin withdrawal. Other studies indicate that melatonin sensitises the PT cell to the stimulatory effect of adenosine, positively regulating the intracellular responses in the light phase (von Gall et al. 2002). This shows that the nocturnal melatonin signal induces both inhibitory and stimulatory effects through cAMP signalling, resulting in a different output according to signal duration under long and short photoperiods. Overall, the results are consistent with a decoder based on amplitude of gene expression (Fig. 3a).

\section{Clock genes and clockwork in the PT calendar cell}

The initial studies that measured the 24-h patterns of Per1 gene expression in the PT used the Period gene as an example of a rapidly inducible gene, rather than a 


\section{a) amplitude modulation (hamster)}
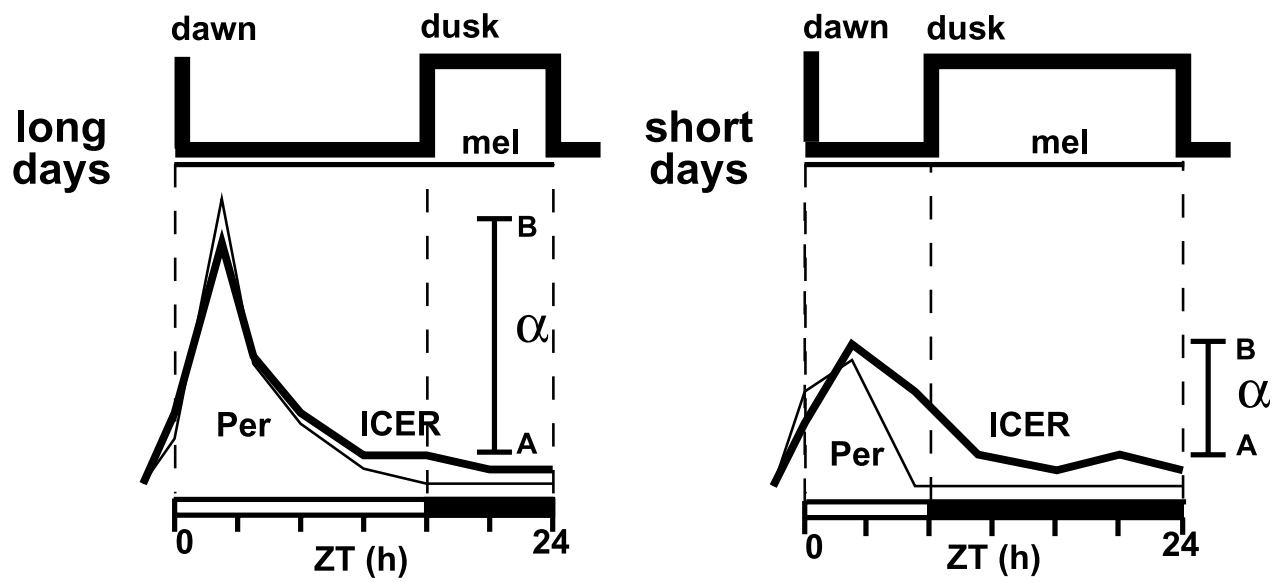

\section{b) phase control (sheep)}
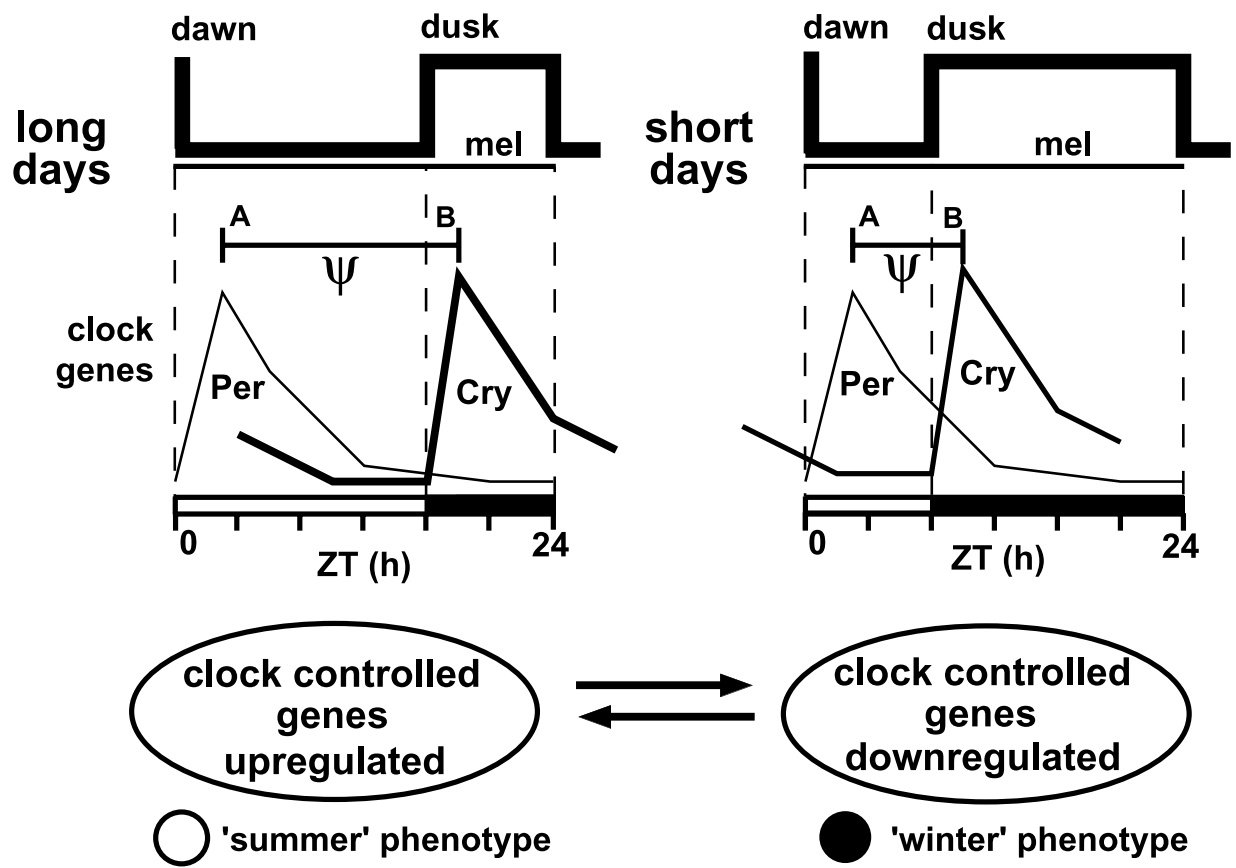

Figure 3 Decoding the melatonin signal in calendar cells involves changes in the temporal expression of circadian clock elements. In the amplitude model based on the hamster (a), suppression of Per and associated early response gene ICER by SD affects the amplitude of gene expression $(A-B, \alpha)$, and this may result in an up- or down-regulation of gene transcription to produce the summer/winter phenotype. In the phase control sheep model (b), changes in the phase of Per and Cry gene expression are driven by the shifts in the offset and onset of melatonin secretion. The Per/Cry interval (A-B, $\psi)$ thus varies with photoperiod with downstream consequences for the regulation of clock-controlled genes and the seasonal output.

component of a circadian clockwork mechanism as described in the SCN. Most recently, the expression profiles for multiple clock genes (Bmal1, Clock, Per1, Per2, Cry1, Cry 2, Ck1E) have been determined for the ovine PT in animals exposed to both long and short photoperiods (Lincoln et al. 2002). This study showed that all the selected clock genes were expressed in the PT with a high amplitude pattern of rhythmicity irrespective of 
photoperiod. However, photoperiod markedly affects the relative timing of clock gene expression in the PT. Here, peak expression of the Period genes (Per1 and Per2) occurs in the early light phase (ZT 3-7), as seen in seasonal rodents, while the peak in expression of the Cryptochrome genes (Cry 1 and $C r y 2)$ occurs in the dark phase under both long and short photoperiods. These changes were closely correlated with the blood concentrations of melatonin, with the activation of Per 1 associated with the decline in melatonin after lights-on, and the activation of Cry 1 associated with the increase in melatonin after lights-off. The temporal control of the Pers is consistent with a dis-inhibition mechanism, while the control of the Crys may implicate a stimulatory genomic action of melatonin presumably involving a different intracellular relay. The causal link between melatonin onset and Cry activation is further supported by the most recent observation that a delay in the timing of lights-out by $8 \mathrm{~h}$ suppresses melatonin and produces an immediate delay in the peak in Cry 1 expression.

The differential regulation of Per and Cry genes now provides an alternative phase control mechanism for decoding melatonin duration in the target tissue (Fig. 3b). Because the activation of Per genes is locked to dawn, and the activation of Cry genes is locked to dusk, the Per/Cry interval $(\psi)$ varies directly with photoperiod. In the SCN, the protein products of these genes are known to form heterodimeric complexes that accumulate in the cytoplasm, before gaining entry into the nucleus to regulate transcription of target genes (Kume et al. 1999). No similar studies have been carried out in the PT, but the presumption is that melatonin regulation of the Per/Cry interval in the PT will affect the daily maximum concentration of PER/CRY heterodimers, and thus the transcriptional control of downstream genes specific to the function of the PT cell (Fig. 3b).

\section{Interval timer/circannual rhythm generator in the PT calendar cell}

Comprehensive in vivo studies in HPD sheep provide further evidence that there is an interval timer and/or circannual rhythm generator within the PT (Lincoln \& Clarke 1994, 1997, 2000). In the HPD animal, the pituitary gland is physically isolated from the hypothalamus by the surgical removal of the arcuate nucleus and destruction of the median eminence (Clarke et al. 1983, Lincoln et al. 2001). The superior hypophyseal artery is retained to support a viable pituitary gland. This includes the PT that continues to express melatonin receptors (Williams et al. 1997), and the pars distalis/pars intermedia with all the secretory cell types that become more or less active, according to the nature of the neural control operating in the intact animal (Lincoln \& Richardson 1998).
The HPD operation blocks the photoperiodic control of all pituitary functions with the exception of the regulation of prolactin secretion. Thus, HPD sheep specifically express long-term cycles in blood concentrations of prolactin in response to changes in photoperiod - increased under LD and decreased under SD, a pattern remarkably similar in timing and amplitude to intact controls (Lincoln \& Clarke 1997, 2000). Treatments with systemic, constant-release implants of melatonin readily inhibit prolactin release in HPD sheep, and mimic the effects of SD (Lincoln et al. 1996a). These responses occur despite pharmacological evidence that both the hypothalamic dopamine and noradrenaline systems, that normally provide prolactin homeostasis, are no longer functioning in the HPD animal (Lincoln \& Clarke 2002). Because melatonin receptors are still expressed at high density in the PT, and apparently not by lactotrophs (Williams et al. 1997), and because HPD animals have normal 24-h melatonin profiles (Lincoln \& Clarke 2000, Lincoln et al. $2003 a$ ), it is inferred that photoperiod dictates the pattern of melatonin release into the peripheral blood, and this signal acts in the PT to indirectly govern long-term prolactin secretion.

These studies also support the hypothesis that there is a free-running annual timer operating in the ovine PT. Exposure of HPD sheep to prolonged constant photoperiod or to constant-release implants of melatonin for 48 weeks, results in a progressive cycle in prolactin secretion (Lincoln \& Clarke 1997, 2000). This is most conspicuous in HPD animals transferred from SD to prolonged LD, where there is an initial phase of increasing blood concentrations of prolactin until week 8-12 (photoinduction), followed by a gradual decline to a nadir at week 32-36 (photorefractoriness), and then a subsequent reactivation (evidence of a circannual timer). The timing was strikingly similar between individuals (Lincoln \& Clarke 2000). The measurement of melatonin confirmed that the 24-h melatonin signal was constant throughout the period of LD. Since the control of prolactin is assumed to reside in the PT in the HPD model, the conclusion is that the PT cell acts as an interval timer. Blockade of prolactin secretion for 12 weeks in HPD sheep under constant LD did not alter the long-term timekeeping, supporting the concept that the timer resides in the PT calendar cell rather than the lactotroph cells (Lincoln et al. 2003a). Moreover, current experiments in HPD sheep demonstrate that cycles in prolactin secretion continue to oscillate with a period of 10-12 months under constant LD (Lincoln et al. 2003b, G A Lincoln, unpublished results) providing the first clear evidence that the PT cell is capable of circannual rhythm generation.

In vitro studies in the Syrian hamster pituitary lend further weight to an argument for an intrinsic timer in the PT. Co-culture of PT tissue with lactotroph cells drives prolactin gene transcription and prolactin secretion, with augmented secretion of tuberalins when tissue is derived 
from long photoperiod-exposed animals (Stirland et al. 2001). In short photoperiod-derived tissue, tuberalin activity is low following 12 weeks of SD, but in tissue derived from short day refractory animals (28 weeks short photoperiod exposure), tuberalin activity is again increased to LD levels, despite the fact that this tissue has been exposed to persistent SD melatonin signals (Johnston et al. 2003). Thus, the spontaneous reactivation of the endocrine axis in vivo is mimicked in vitro in terms of changed tuberalin secretion from this melatonin target site. A parallel phenomenon has been observed in Siberian hamster PT cells, where the spontaneous reactivation of the lactotrophs under prolonged SD is preceded by an increase in common $\alpha$-subunit mRNA and protein in the PT (Bockers et al. 1997).

\section{Location of other calendar cells involved in long-term timekeeping}

Different types of calendar cells strategically placed in the brain, pituitary gland and possibly elsewhere are thought to control discrete components of seasonal physiology, and generate the system-specific timing characteristics. This concept is summarised in Fig. 4. For the prolactin axis, the calendar cell in the PT is in close proximity to the effector - the lactotroph. The prolactin product acts systemically in multiple target tissues to produce the overt biological responses, and acts at the level of the hypothalamus to provide homeostatic control. The very rapid response time of a few days between a switch in photoperiod or manipulation of melatonin, and an initial change in prolactin secretion (Lincoln et al. 1978) is consistent with this direct control between the PT and the lactotroph. This relay is relatively simple and may be shared as an ancestral mechanism across all seasonal mammalian species (Hinds \& Loudon 1997, Lincoln 1999).

For the seasonal control of the gonadotrophin/gonadal axis, the timer cells appear to be located in the brain and not the pituitary gland (Fig. 4b). This is deduced from experimental studies of the effects of stereotaxic lesions and/or the localised administration of melatonin in specific sites in the hypothalamus. For example, in the Syrian hamster electrolytic lesions in the melatonin binding area of the dorsal $\mathrm{MBH}$, but not in other hypothalamic sites, block the photoperiodic control of testicular activity, and render animals unresponsive to programmed infusions of melatonin (Maywood \& Hastings 1995). In sheep, microimplants placed in the $\mathrm{MBH}$, but not in the preoptic area, lateral hypothalamus or pituitary gland, activate gonadotrophin secretion in animals maintained under LD (Lincoln \& Maeda 1992a,b, Malpaux et al. 1995, 1998); here, the premammillary hypothalamus is regarded as the site generating the photoperiodic response and, specifically, the serotonin $2 \mathrm{~A}$ receptor system in this area varies with seasonal changes in LH pulsatility (Chemineau et al. 2003). Cerebral microimplants of melatonin placed in different regions of the brain in the Siberian hamster have also been shown to cause a local photorefractory response while leaving other centres still melatonin responsive, indicating that melatonin acts at several locations in the hypothalamus to govern the reproductive axis (Freeman \& Zucker 2001).

The phenotype of the reproductive timer cells has not been identified in any species, but dopaminergic and/or opiodergic (pro-opiomelanocortin (POMC)) neurones are likely candidates (Goodman et al. 2002, Lincoln 2002, Thiery et al. 2002). These are thought to modulate the release of gonadotrophin releasing hormone $(\mathrm{GnRH})$ from the hypothalamus and thus control gonadotrophin secretion and the gonadal axis. Homeostasis is provided by the feedback effects of gonadal steroids and inhibin-like peptides acting at the level of both the hypothalamus and the pituitary gland (Tilbrook et al. 1999). The photoperiodic control of the reproductive axis is characterised by slow response times of many weeks, unlike the fast prolactin responses, which presumably reflects the more complex neuroendocrine relay and the clamping inhibitory effects of gonadal steroid hormones (Lincoln 1999, Billings et al. 2002). Differences in the hypothalamic neural network that provides the time-keeping may account for the wide spectrum of species differences, whereby the initial photoinductive effect of LD (short daily melatonin signal) is stimulatory to $\mathrm{GnRH} /$ gonadotrophin secretion in LD breeders, but inhibitory in SD breeders.

The clear difference in the timer cells controlling gonadotrophin and prolactin secretion is well illustrated by studies on the effects of thyroidectomy in sheep and deer (Anderson \& Barrell 1998, Billings et al. 2002). Removal of the thyroid markedly affects the photoinduction/ refractory responses for the control of gonadotrophin secretion, but with no effect on prolactin cyclicity. This fits with the view that the timer for the reproductive axis, unlike that for prolactin, is neurally based and linked to the effectors through synaptic relays that are thyroxine dependent.

The time-keeping mechanisms underlying the longterm regulation of cycles in body weight and energy balance are the least resolved (Fig. 4c). The general consensus from studies in rodents and sheep is that the timers for the control of body weight and energy balance reside in the hypothalamus, and are multiple. In sheep, the expression of the appetite regulatory peptides, neuropeptide Y (NPY) and agouti related protein (AGRP) in the arcuate nucleus, and orexin in the lateral hypothalamus, are modulated by photoperiod consistent with a role in the seasonal control of food intake and body weight (Archer et al. 2002, Clarke et al. 2003). The administration of melatonin locally in the $\mathrm{MBH}$ in sheep under LD, phase-shifts the body weight cycle (Lincoln \& Maeda 1992b), and lesion of the arcuate nucleus blocks both the photoperiodic and homeostatic control of voluntary food 


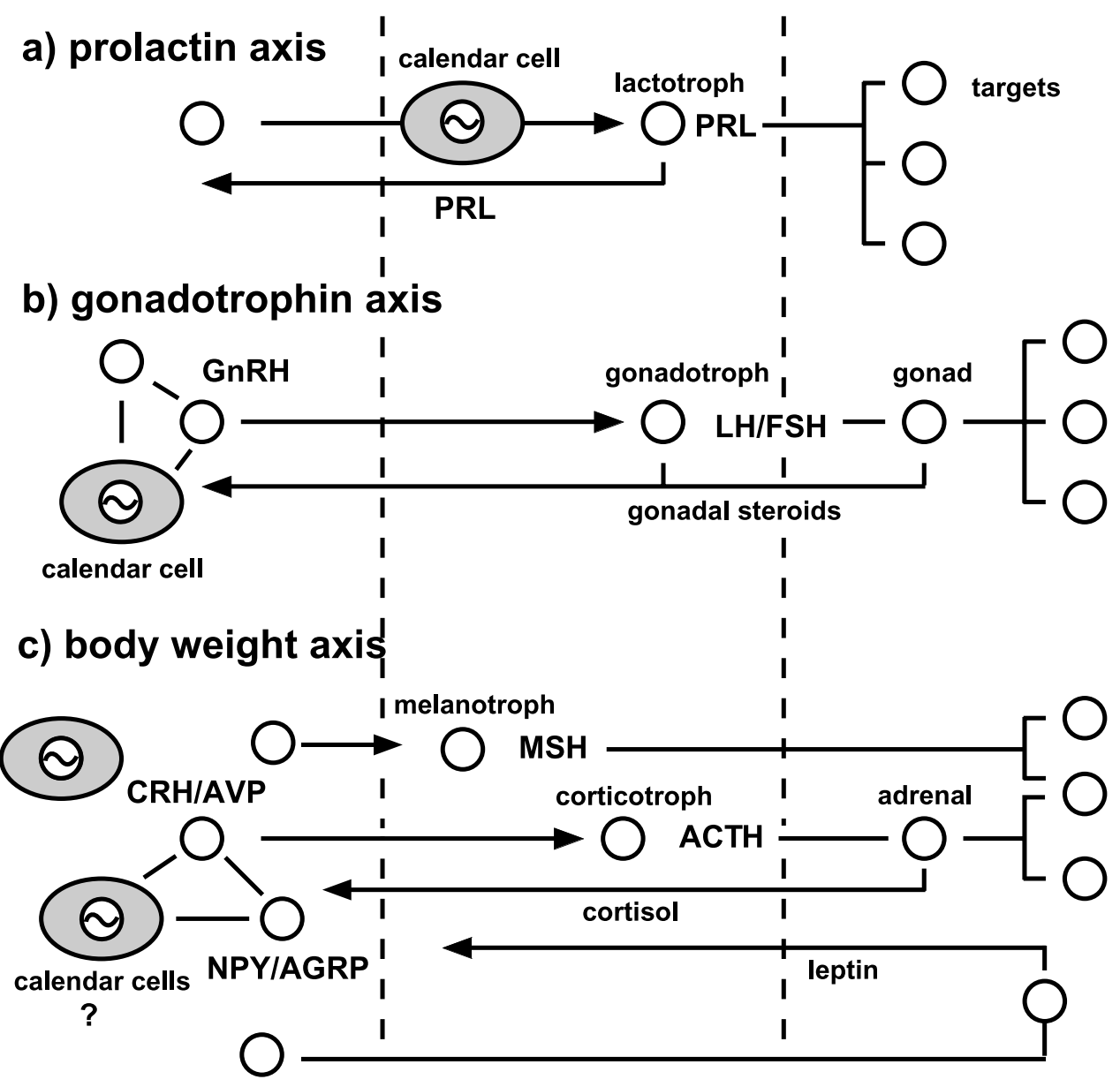

$\begin{array}{llll}\text { brain } & \text { pituitary } & \text { i } & \text { peripheral } \\ \text { gland } & \text { tissues }\end{array}$

Figure 4 Calendar timer cells are presumed to reside in the brain, pituitary gland and perhaps peripheral tissues. The relay system in the pituitary gland controlling prolactin (a) provides a rapid response to the melatonin signal change, common to all seasonal mammals. In the brain, calendar cells involving the reproductive and metabolic control (b, c), may be networked via neural pathways, providing for a more complex response to melatonin, and thus species diversity in terms of breeding season and fattening responses. The schemes are conceptual rather than specific. Calendar cells are yet to be identified in peripheral tissues, but clearly defined hormone target sites such as the hair follicle and testis (prolactin sensitive tissues) may be attractive candidates for such investigations. PRL, prolactin; LH/FSH, luteinising hormone/follicle-stimulating hormone; MSH, melanocyte-stimulating hormone; ACTH, adrenocorticotrophin; $\mathrm{CRH} / \mathrm{AVP}$, corticotrophin-releasing hormone/arginine vasopressin.

intake and body weight (Lincoln et al. 2001). In the small seasonal hamster models, the regulatory centres of the ventral hypothalamus do not appear to be critically involved in seasonal weight regulation, and leptin feedback does not provide a key component in seasonal weight regulation (Rousseau et al. 2003). Sympathetic nervous system control of fat storage sites and thermoregulatory centres may be more important
(Bartness et al. 2002). The melatonin-responsive cells of the SCN are also implicated, as lesions in the SCN of Siberian hamsters block melatonin-induced changes in lipogenesis (Bittman et al. 1991). Seasonal and circannual cycles in body weight are notably slow to respond to changes in photoperiod (Loudon 1994), consistent with regulation involving a highly interactive set of control systems (Fig. 4c). 


\section{Generalised model for long-term timing}

The current literature allows us to present a generalised hypothesis for control of photoperiodism and circannual rhythm generation in mammals. This can be summarised by the following conjecture.

Long-term time keeping is dependent on calendar cells strategically located in the brain and pituitary gland that regulate specific components of physiology and behaviour. These calendar cells have different functional phenotypes according to the neural/endocrine system they modulate. The presence of separate multiple seasonal timers which respond to a common melatonin signal is consistent with the observed dissociation in the timing of long-term cycles in prolactin and gonadotrophin secretion following surgery (Lee \& Zucker 1991) or under a constant melatonin signal (Karsch et al. 1989), and in the circannual control of cycles in gonadal activity and body weight under prolonged constant photoperiod (Pengelly \& Amundson 1974).

The calendar cells express a full complement of clock genes that provide the molecular basis of the long-term timer. Distinct from the circadian rhythm generator mechanism, this involves the amplitude and/or phase control of the 24-h rhythms in specific clock genes (e.g. Pers and Crys), where the products form protein-protein complexes that regulate the transcription of a cascade of early response and late response genes, to govern cellular physiology. Calendar cells can be driven by melatonin, or can oscillate between active and inactive states to dictate the long-term cycles in physiology and behaviour.

The timing mechanism in the calendar cell controls the phenomena of photoinduction, photorefractoriness and (in long-lived species) circannual rhythm generation - seen to represent a continuum. The internal coincidence model predicts that the phase-control of clock genes is the critical mechanism for timekeeping, and photoinduction occurs when a change in melatonin signal duration causes a corresponding change in the relative phase of clock gene expression at a target tissue (e.g. relative timing of peak expression of $\mathrm{Per}$ and $\mathrm{Cr} y$ ). The degree of coincidence affects the state of the calendar cell that, in turn, is reflected in altered downstream physiology.

Two distinct hypotheses arise, namely: model A, clock genes in calendar cells have been co-opted to produce a photoperiodic/circannual timer; or model B, clock genes cycles simply report the ambient melatonin rhythm, and separate genetic pathways regulate the downstream seasonal response (see Fig. 5). In the first, photorefractoriness may represent uncoupling of the molecular clockwork from control by melatonin signal, such that circannual rhythms may be generated by intrinsically regulated changes in the relative phases of clock gene expression. Here, the prediction is that clock gene expression in calendar cells will reflect the photorefractory state, or the phase of the circannual cycle, and not the ambient melatonin signal (Fig. 5, model A). Recent studies in PT
Per1 expression in photorefractory Syrian hamsters suggest that this may not be the case in this species as Per1 exhibits an invariant low amplitude profile on SD refractory hamsters (Johnston et al. 2003), but more clock components need to be investigated. In the second model (Fig. 5, model B), the long-term timing mechanism operates as a consequence of the history of repeated exposure to cycles of clock genes (or some other index of time), but the timer is not directly driven by alterations in the phase and/or amplitude of the circadian clock gene complex itself. In both cases, the possibility of a single common mechanism underlying photoperiodism and circannual rhythm generation is consistent with many observations. Notably, circannual rhythms are entrained by photoperiod/melatonin in many mammals, and the development of photorefractoriness merges into the expression of a circannual rhythmicity (Lee \& Zucker 1991, Martinet et al. 1992, Woodfill et al. 1994). The circannual rhythm may be evident under only a restricted range of constant photoperiods (Goss 1977, Howles et al. 1982). In the HPD sheep model, photoinduction, photorefractoriness and circannual rhythm generation are features expressed under constant LD, indicating that the key aspects of long-term time keeping may be regulated within a single melatonin target tissue, and potentially at the level of one calendar cell (e.g. Lincoln et al. 2003b).

Irrespective of whether clock genes are involved in the direct control (model A), or the timing (model B), photorefractory and circannual timers must necessitate the interaction with other genetic mechanisms that govern very long time intervals. This requires slow, incremental regulation by genes over many months, akin perhaps to the molecular mechanisms that control embyonic development organogenesis, and aging (Murphy et al. 2003). In such a gene hierarchy, clock genes may therefore be key elements on the input pathway, but the search for the true long-term time keeping genes has still to begin.

Humans express all elements of photoperiodism and circannual rhythm generation, albeit in a relatively weak fashion compared with many non-primate species (Roenneberg \& Aschoff 1990, Wehr 2001). In man, the cyclicity is revealed as seasonal cycles in birth season, incidence of twinning, semen quality, carbohydrate metabolism and weight gain, and notably as behavioural traits of clinical importance including seasonal affective disorder and bulimia nervosa (Wehr \& Rosenthal 1989, Blouin et al. 1992, Wirz-Justice et al. 2001). Predictably, calendar cells with specific peptide and/or neurotransmitter relays function in the human brain and impact on all our lives.

These generalised statements can now be tested. The challenge is to identify the putative calendar cells that selectively control the overt cycles in reproduction, food intake, fat deposition and other characteristics, and to measure the expression profiles for a full complement of clock genes, as well as their proteins, in these specific cells. The formation of PER/CRY complexes and the 


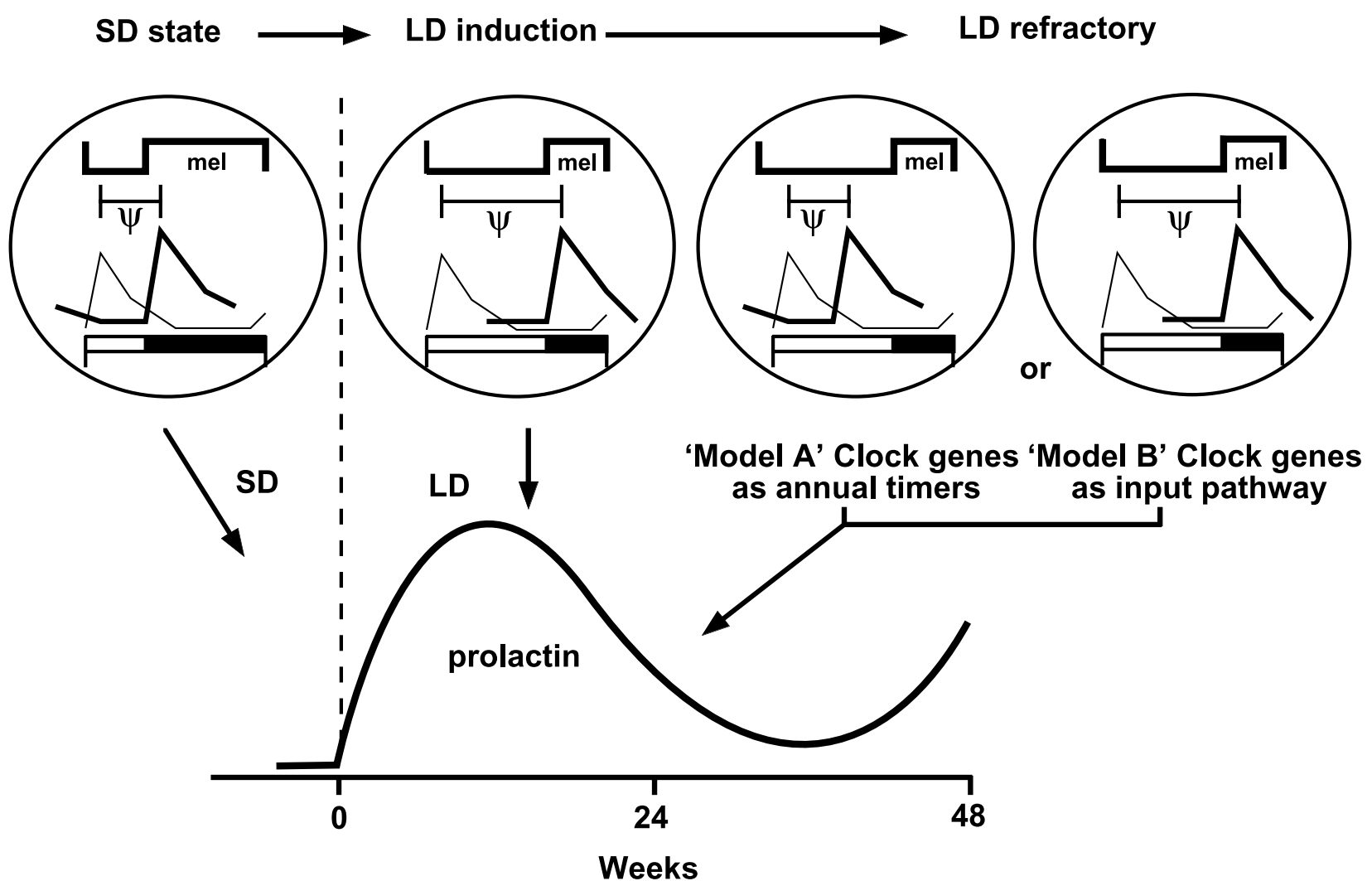

Figure 5 Models of circadian timer gene expression in calendar cells at different phases following a change from a short day (SD) to a long day (LD) photoperiod, resulting in LD induction (0-12 weeks) and LD refractory states (12-32 weeks) based on prolactin output in HPD sheep. In model A, clock genes are entrained by the melatonin signal (input pathway) and constitute the core of the clockwork (output pathway). In refractory animals, clock gene rhythms revert to the SD state ( $\psi$ reduced) by uncoupling from control by the melatonin signal, driving output physiology in reverse. In model B, clock genes merely reflect the pattern of melatonin secretion (input pathway), and other unknown genetic elements provide the timer.

transcriptional control can be investigated. Ex-vivo models may be developed of pituitary explants or other tissues that differentially respond to changes in melatonin duration and in which individual clock genes can be neutralised by RNA interference, to assess the effect on the output responses. The overall aim would be to develop a unifying hypothesis for the operation of clock genes, and determine whether, as proposed in this review, the set of interactive genes originally evolved to form a circadian timer has also been co-opted in long-lived animals to produce a photoperiod/circannual timer.

\section{References}

Anderson GM \& Barrell GK 1998 Effects of thyroidectomy and thyroxine replacement on seasonal reproduction in the red deer hind. Journal of Reproduction and Fertility 113 239-250.

Archer ZA, Findlay PA, Rhind SM, Mercer JG \& Adam CL 2002 Orexin gene expression and regulation by photoperiod in the sheep hypothalamus. Regulatory Peptides 104 41-45.
Bartness TJ, Demas GE \& Song CK 2002 Seasonal changes in adiposity: the roles of the photoperiod, melatonin and other hormones, and sympathetic nervous system. Experimental Biology and Medicine 227 363-376.

Billings HJ, Viguie C, Karsch FJ, Goodman RL, Connors JM \& Anderson GM 2002 Temporal requirements of thyroid hormones for seasonal changes in LH secretion. Endocrinology 143 2618-2625.

Bittman EL, Bartness TJ, Goldman BD \& DeVries GJ 1991 SCN lesions block responses to systemic melatonin infusions in Siberian hamsters. American Journal of Physiology 260 R102-R112.

Blouin A, Blouin J \& Aubin P 1992 Seasonal patterns of bulimia nervosa. American Journal of Psychiatry 149 73-81.

Bockers TM, Bockmann J, Salem A, Niklowitz P, Lerchl A, Huppertz M, Wittkowski W \& Kreutz MR 1997 Initial expression of the common alpha-chain in hypophyseal pars tuberalis-specific cells in spontaneous recrudescent hamsters. Endocrinology 138 4101-4108.

Chemineau P, Daveau A, Pelletier J, Malpaux B, Karsch FJ \& Viguie C 2003 Changes in the 5-HT2A receptor system in the premammillary hypothalamus of the ewe are related to regulation of LH pulsatile secretion by an endogenous circannual rhythm. BMC Neuroscience 41.

Clarke IJ, Cummins JT \& de Kretser DM 1983 Pituitary gland function after disconnection from direct hypothalamic influences in sheep. Neuroendocrinology 36 376-384. 
Clarke IJ, Rao A, Chilliard Y, Delavaud C \& Lincoln GA 2003 Photoperiod effects on gene expression for hypothalamic appetiteregulating peptides and food intake in the ram. American Journal of Physiology. Regulatory, Integrative and Comparative Physiology 284 R101-R115.

Freeman DA \& Zucker I 2001 Refractoriness to melatonin occurs independently at multiple brain sites in Siberian hamsters. PNAS 98 6447-6452.

von Gall C, Garabette ML, Kell CA, Frenzel S, Dehghani F, Schumm-Draeger PM, Weaver DR, Korf HW, Hastings MH \& Stehle JH 2002 Rhythmic gene expression in pituitary depends on heterologous sensitization by the neurohormone melatonin. Nature Neuroscience 5 234-238.

Goldman BD 2001 Mammalian photoperiodic system: formal properties and neuroendocrine mechanisms of photoperiodic time measurement. Journal of Biological Rhythms 16 283-301.

Goodman RL, Gibson M, Skinner DC \& Lehmen MN 2002 Neuroendocrine control of pulsatile GnRH secretion during the ovarian cycle: evidence from the ewe. Reproduction Supplement 59 41-56.

Goss RJ 1977 Photoperiodic control of antler cycles in deer. (iv) Effects of constant light:dark ratios on circannual rhythms. Journal of Experimental Zoology 201 379-383.

Gwinner E 1986 Circannual Rhythms: Endogenous Annual Clocks in the Organization of Seasonal Processes. Berlin, Heildelberg: SpringerVerlag.

Hazlerigg DG, Gonzalez-Brito A, Lawson W, Hastings MH \& Morgan PJ 1993 Prolonged exposure to melatonin leads to time-dependent sensitization of adenylate cyclase and downregulates melatonin receptors in pars tuberalis cells from ovine pituitary. Endocrinology 132 285-292.

Hazlerigg DG, Hastings MH, \& Morgan PJ 1996 Production of a prolactin releasing factor by the ovine pars tuberalis. Journal of Neuroendocrinology 8 489-492.

Hazlerigg DG, Morgan PJ \& Messager S 2001 Decoding photoperiodic time and melatonin in mammals: what can we learn from the pars tuberalis? Journal of Biological Rhythms 16 326-335.

Hinds LA \& Loudon ASI 1997 Mechanisms of seasonality in marsupials: a comparative view. In Marsupial Biology - Recent Research, New Perspectives, pp 41-70. Eds NR Saunders \& LA Hinds. Sydney: UNSW Press.

Howles CM, Craigon H \& Haynes NB 1982 Long-term rhythms of testicular volume and plasma prolactin concentrations in rams reared for three years in constant photoperiod. Journal of Reproduction and Fertility 65 439-446.

Illnerova H \& Sumova A 1997 Photic entrainment of the mammalian rhythm in melatonin production. Journal of Biological Rhythms 12 547-555.

Johnston JD, Cagampang FRA, Stirland JA, Carr AJF, White MRH, Davis JRE \& Loudon ASI 2003 Evidence for an endogenous Per1 and ICER-independent seasonal timer in the hamster pituitary gland. FASEB Journal 17 810-815.

Karsch FJ, Robinson JE, Woodfill CJ \& Brown MB 1989 Circannual cycles of luteinizing hormone and prolactin secretion in ewes during prolonged exposure to a fixed photoperiod: evidence for an endogenous reproductive rhythm. Biology of Reproduction $\mathbf{4 1}$ 1034-1046.

Klein DC, Coon SL, Roseboom PH, Weller JL, Bernard M, Gastel JA, Zatz M, Iuvone PM, Rodriguez IR, Begay V, Falcon J et al. 1997 The melatonin rhythm-generating enzyme: molecular regulation of serotonin $\mathrm{N}$-acetyltransferase in the pineal gland. Recent Progress in Hormone Research 52 307-357.

Kuhlmann MT, Clemen G \& Schlatt S 2003 Molting in the Djungarian hamster (Phodopus sungorus, Pallas): seasonal or continuous process? Journal of Experimental Zoology. Part A, Comparative Experimental Biology 295 160-171.
Kume K, Zylka MJ, Sriram S, Shearman LP, Weaver DR, Jin X, Maywood ES, Hastings MH \& Reppert SM 1999 mCRY1 and mCRY2 are essential components of the negative limb of the circadian clock feedback loop. Cell 98 193-205.

Lee TM \& Zucker I 1991 Suprachiasmatic nucleus and photic entrainment of circannual rhythms in ground squirrels. Journal of Biological Rhythms 6 315-330.

Lincoln GA 1999 Melatonin modulation of prolactin and gonadotrophin secretion. Systems ancient and modern. Advances in Experimental Medicine and Biology 460 137-153.

Lincoln GA 2002 Neuroendocrine regulation of seasonal gonadotrophin and prolactin rhythms: lessons from the Soay ram model. Reproduction Supplement 19 131-147.

Lincoln GA \& Clarke IJ 1994 Photoperiodically-induced cycles in the secretion of prolactin in hypothalamo-pituitary disconnected rams: evidence for translation of the melatonin signal in the pituitary gland. Journal of Neuroendocrinology 6 251-260.

Lincoln GA \& Clarke IJ 1997 Refractoriness to a static melatonin signal develops in the pituitary gland for the control of prolactin secretion in the ram. Biology of Reproduction 57 460-467.

Lincoln GA \& Clarke IJ 2000 Role of the pituitary gland in the development of photorefractoriness and generation of long-term changes in prolactin secretion in rams. Biology of Reproduction $\mathbf{6 2}$ 432-448.

Lincoln GA \& Clarke IJ 2002 Noradrenaline and dopamine regulation of prolactin secretion in sheep: role in prolactin homeostasis but not photoperiodism. Journal of Neuroendocrinology 14 36-44.

Lincoln GA \& Maeda KI 1992a Reproductive effects of placing micro-implants of melatonin in the mediobasal hypothalamus and preoptic area in rams. Journal of Endocrinology 132 201-215.

Lincoln GA \& Maeda K $1992 b$ Effects of placing micro-implants of melatonin in the mediobasal hypothalamus and preoptic area on the secretion of prolactin and beta-endorphin in rams. Journal of Endocrinology 134 437-448.

Lincoln GA \& Richardson M 1998 Photo-neuroendocrine control of seasonal cycles in body weight, pelage growth and reproduction: lessons from the HPD sheep model. Comparative Biochemistry and Physiology. Part C, Pharmacology, Toxicology and Endocrinology 119 283-294.

Lincoln GA, McNeilly AS \& Cameron CL 1978 The effects of a sudden decrease or increase in daylength on prolactin secretion in the ram. Journal of Reproduction and Fertility 52 305-311.

Lincoln GA, Clarke IJ \& Sweeney T 1996a 'Hamster-like' cycles in testicular size in the absence of gonadotrophin secretion in HPD rams exposed to long-term changes in photoperiod and treatment with melatonin. Journal of Neuroendocrinology 8 855-866.

Lincoln GA, Dayawansa N \& Ratnasooriya WD 1996 b Antler cycles in male axis deer, Axis axis, living in Sri Lanka close to the equator. In Biology of Deer. Ed J Milne. MLURI, Edinburgh: McCaulay Land Use Research Institute Publication.

Lincoln GA, Rhind SM, Pompolo S \& Clarke IJ 2001 Hypothalamic control of photoperiod-induced cycles in food intake, body weight, and metabolic hormones in rams. American Journal of Physiology. Regulatory, Integrative and Comparative Physiology 281 R76-R90.

Lincoln G, Messager S, Andersson H \& Hazlerigg D 2002 Temporal expression of seven clock genes in the suprachiasmatic nucleus and the pars tuberalis of the sheep: evidence for an internal coincidence timer. PNAS 99 13890-13895.

Lincoln GA, Andersson H \& Clarke IJ 2003a Prolactin cycles in sheep under constant photoperiod: evidence that photorefractoriness develops within the pituitary gland independently of the prolactin output signal. Biology of Reproduction (In Press).

Lincoln GA, Andersson H \& Hazlerigg D 2003b Clock genes and the long-term regulation of prolactin secretion: evidence for a photoperiod/circannual timer in the pars tuberalis. Journal of Neuroendocrinology 15 390-397.

Loudon ASI 1994 Photoperiod and regulation of annual and circannual cycles of food intake. Proceedings of the Nutrition Society 53 477-489. 
Loudon ASI \& Curlewis JD 1988 Cycles of antler and testicular growth in an aseasonal tropical deer (Axis axis). Journal of Reproduction and Fertility 83 729-738.

McNulty S, Ross AW, Barrett P, Hastings MH \& Morgan PJ 1994 Melatonin regulates the phosphorylation of CREB in ovine pars tuberalis. Journal of Neuroendocrinology 6 523-532.

Malpaux B, Skinner DC \& Maurice F 1995 The ovine pars tuberalis does not appear to be targeted by melatonin to modulate luteinizing hormone secretion, but may be important for prolactin release. Journal of Neuroendocrinology 7 199-206.

Malpaux B, Daveau A, Maurice-Mandon F, Duarte G \& Chemineau P 1998 Evidence that melatonin acts in the premammillary hypothalamic area to control reproduction in the ewe: presence of binding sites and stimulation of luteinizing hormone secretion by in situ microimplant delivery. Endocrinology 139 1508-1516.

Malpaux B, Migaud M, Tricoire H \& Chemineau P 2001 Biology of mammalian photoperiodism and the critical role of the pineal gland and melatonin. Journal of Biological Rhythms 16 336-347.

Martinet L, Mondain-Monval M \& Monnerie R 1992 Endogenous circannual rhythms and photorefractoriness of testis activity, moult and prolactin concentration in mink (Mustella vison). Journal of Reproduction and Fertility 95 325-338.

Maywood ES \& Hastings MH 1995 Lesions of the iodomelatoninbinding sites of the mediobasal hypothalamus spare the lactotropic, but block the gonadotropic response of male Syrian hamsters to short photoperiod and to melatonin. Endocrinology 136 144-153.

Messager S, Ross AW, Barrett P \& Morgan PJ 1999 Decoding photoperiodic time through Per1 and ICER gene amplitude. PNAS 96 9938-9943

Messager S, Hazlerigg DG, Mercer JG \& Morgan PJ 2000 Photoperiod differentially regulates the expression of Per1 and ICER in the pars tuberalis and the suprachiasmatic nucleus of the Siberian hamster. European Journal of Neuroscience 12 2865-2870.

Messager S, Garabette ML, Hastings MH \& Hazlerigg DG 2001 Tissue-specific abolition of Per1 expression in the pars tuberalis by pinealectomy in the Syrian hamster. Neuroreport 12 579-582.

Morgan PJ 2000 The pars tuberalis: the missing link in the photoperiodic regulation of prolactin secretion. Journal of Neuroendocrinology 12 287-295.

Morgan PJ \& Mercer JG 2002 The regulation of body weight: lessons from the seasonal animal. Proceedings of the Nutrition Society $\mathbf{6 0}$ $127-134$.

Morgan PJ, Barrett P, Howell HE \& Helliwell R 1994 Melatonin receptors: localization, molecular pharmacology and physiological significance. Neurochemistry International 24 101-146.

Morgan PJ, Webster CA, Mercer JG, Ross AW, Hazlerigg DG, MacLean A \& Barrett P 1996 The ovine pars tuberalis secretes a factor(s) that regulates gene expression in both lactotropic and nonlactotropic pituitary cells. Endocrinology 137 4018-4026.

Morgan PJ, Ross AW, Graham ES, Adam C, Messager S \& Barrett P 1998 oPer1 is an early response gene under photoperiodic regulation in the ovine pars tuberalis. Journal of Neuroendocrinology $\mathbf{1 0}$ 319-323.

Murphy CT, McCarroll SA, Bargmann CI, Fraser A, Kamath RS, Ahringer J, Li H \& Kenyon C 2003 Genes that act downstream of DAF-16 to influence the lifespan of Caenorhabditis elegans. Nature 424 277-284.

Nuesslein-Hildesheim B, O'Brien JA, Ebling FJ, Maywood ES \& Hastings MH 2000 The circadian cycle of mPER clock gene products in the suprachiasmatic nucleus of the Siberian hamster encodes both daily and seasonal time. European Journal of Neuroscience 12 2856-2864.

Pengelly ET \& Amundson SJ 1974 Circannual rhythmicity in hibernating animals. In Circannual Clocks: Annual Biological Rhythms, pp 96-160. Ed ET Pengelly. New York: Academic Press.

Picazo RA \& Lincoln GA 1995 Light control of the duration of the daily melatonin signal under long and SD in the Soay ram. Role of inhibition and entrainment. Journal of Biological Rhythms 10 55-63.

Prendergast BJ, Mosinger B Jr, Kolattukudy PE \& Nelson RJ 2002 Hypothalamic gene expression in reproductively photoresponsive and photorefractory Siberian hamsters. PNAS 99 16291-16296.

Reppert SM \& Weaver DR 2002 Coordination of circadian timing in mammals. Nature 418 935-941.

Reppert SM, Weaver DR \& Ebisawa T 1994 Cloning and characterization of a mammalian melatonin receptor that mediates reproductive and circadian responses. Neuron 13 1-20.

Roenneberg T \& Aschoff J 1990 Annual rhythm of human reproduction: II. Environmental correlations. Journal of Biological Rhythms 5 217-239.

Rousseau K, Atcha Z \& Loudon ASI 2003 Leptin and seasonal mammals. Journal of Neuroendocrinology 15 (In Press).

Stehle JH, von Gall C, Schomerus C \& Korf HW 2001 Of rodents and ungulates and melatonin: creating a uniform code for darkness by different signalling mechanisms. Journal of Biological Rhythms 16 312-325.

Stirland JA, Johnston JD, Cagampang FR, Morgan PJ, Castro MG, White MR, Davis JR \& Loudon AS 2001 Photoperiodic regulation of prolactin gene expression in the Syrian hamster by a pars tuberalis-derived factor. Journal of Neuroendocrinology 13 147-157.

Sumova A, Travnickova Z, Peters R, Schwartz WJ \& Illnerova H 1995 The rat suprachiasmatic nucleus is a clock for all seasons. PNAS 92 7754-7758.

Tamarkin L, Baird CJ \& Almeida OF 1985 Melatonin: a coordinating signal for mammalian reproduction? Science 227 714-720.

Thiery JC, Chemineau P, Hernandez X, Migaud M \& Malpaux B 2002 Neuroendocrine interactions and seasonality. Domestic Animal Endocrinology 23 87-100.

Tilbrook AJ, de Kretser DM \& Clarke IJ 1999 Seasonal changes in the negative feedback regulation of the secretion of the gonadotrophins by testosterone and inhibin in rams. Journal of Endocrinology $\mathbf{1 6 0}$ 155-167.

Wehr TA 2001 Photoperiodism in humans and other primates: evidence and implications. Journal of Biological Rhythms 16 348-364.

Wehr TA \& Rosenthal NE 1989 Seasonality and affective illness. American Journal of Psychiatry 146 829-839.

Williams LM, Lincoln GA, Mercer JG, Barrett P, Morgan PJ \& Clarke IJ 1997 Melatonin receptors in the brain and pituitary gland of hypothalamo-pituitary disconnected Soay rams. Journal of Neuroendocrinology 9 639-643.

Wirz-Justice A, Krauchi K \& Graw P 2001 An underlying circannual rhythm in seasonal affective disorder? Chronobiology International $\mathbf{1 8}$ 309-313.

Woodfill CJ, Wayne NL, Moenter SM \& Karsch FJ 1994 Photoperiodic synchronization of a circannual reproductive rhythm in sheep: identification of season-specific time cues. Biology of Reproduction 50 965-976.

Received 24 February 2003

Accepted 26 June 2003 